\title{
PEMBUATAN KOMPOS DARI CAMPURAN 60\% BERAT TANDAN KOSONG KELAPA SAWIT DAN $40 \%$ BERAT AZOLLA MICROPHYLLA DENGAN BANTUAN PUPUK CAIR ORGANIK AKTIF
}

\author{
COMPOSTING MAKING FROM 60\% OF WEIGHT EMPTY FRUIT BUNCHES AND 40\% \\ OF WEIGHT AZOLLA MICROPHYLLA WITH ASISTANCE ACTIVE ORGANIC LIQUID \\ FERTILIZER
}

\author{
Andry Hammonang Sianturi*, Immanuel Putra Riau Hutagaol, Bambang Trisakti, Irvan \\ Departemen Teknik Kimia, Fakultas Teknik, Universitas Sumatera Utara \\ Jl. Almamater Kampus USU Medan 20155 Indonesia \\ *Email: andryhsianturi@ymail.com
}

\begin{abstract}
Abstrak
Proses pengomposan tandan kosong kelapa sawit dan azolla microphylla dengan bantuan pupuk cair organik aktif merupakan alternatif pemanfaatan limbah padat yang dihasilkan dari pabrik kelapa sawit. Penelitian ini bertujuan untuk memproduksi kompos bermutu baik dari campuran 60\%:40 \% berat tandan kosong kelapa sawit dan azolla microphylla dengan bantuan pupuk cair organik. Proses pengomposan dilakukan dengan memasukkan tandan kosong kelapa sawit dan Azolla microphylla pada komposter dan ditambahkan dengan pupuk cair organic aktif hingga nilai moisture content $55 \%-65 \%$. Selama pengomposan moisture content dijaga pada kondisi dengan menambahkan pupuk cair organic aktif. Parameter yang dianalisa adalah temperatur, moisture content, $\mathrm{pH}$, water holding capacity, electrical conductivity, dan $C-N$. Hasil penelitian menunjukkan bahwa kompos dapat dihasilkan dalam waktu \pm 30 hari dengan karakteristik pH 8,8; Moisture Content 59,92\%, Water Holding Capacity 86\%, C $27,24 \%, N 1,53 \%$ dan $C / N 17,80 \%$
\end{abstract}

Kata kunci: tandan kosong kelapa sawit, Azolla microphylla, pupuk cair organik aktif, komposter, moisture content.

\begin{abstract}
The process of composting empty fruit bunches and Azolla microphylla by asistance active organic liquid fertilizer was an alternative in the utilization of solid waste produced from the palm oil mill. This research was to produce good quality compost from a mixture of 60\%:40\% weight empty fruit bunches and azolla microphylla with asistance active organic liquid fertilizer. The composting process is done by entering empty fruit bunches and Azolla microphylla on the composter and added active organic liquid fertilizer to achieve the moisture content value of 55\%-65\%. During composting, the moisture content was kept on the optimum condition by adding the active organic liquid fertilizer. The parameters analyzed were temperature, moisture content, $\mathrm{pH}$, water holding capacity, electrical conductivity, and $C-N$. The result showed that compost can be produced within \pm 30 days with characteristic of $p H 8.8$; Moisture Content 59,92\%, Water Holding Capacity 86\%, C 27.24\%, N 1.53 $\%$ and $\mathrm{C} / \mathrm{N} 17.80 \%$
\end{abstract}

Keywords : empty fruit bunches, Azolla microphylla, active organic liquid fertilizer, composter,
moisture content.

\section{Pendahuluan}

Tanaman kelapa sawit merupakan salah satu jenis tanaman perkebunan yang menduduki posisi penting dalam sektor pertanian dan sektor perkebunan. Kelapa sawit merupakan komoditi andalan Indonesia yang perkembangannya demikian pesat. Lahan yang optimal untuk kelapa sawit harus mengacu pada tiga faktor yaitu lingkungan, sifat fisik lahan dan sifat kimia tanah atau kesuburan tanah [1].

Pada proses pengolahannya, selain menghasilkan CPO dan inti sawit, pabrik kelapa sawit juga menghasilkan limbah, yaitu limbah cair (palm oil mill effluent, POME) dan padat seperti tandan kosong kelapa sawit (TKKS), fiber, dan cangkang. Menurut Baharudin et al., setiap pengolahan tandan buah segar akan dihasilkan TKKS sebanyak 23\% dari total limbah [2].

Sebelumnya, TKKS dibakar pada incinerator untuk diabukan. Abu hasil pembakaran TKKS dapat digunakan sebagai pupuk, karena kandungan kaliumnya relatif tinggi yakni $\pm 30 \%$. Namun, proses pembakaran ini sekarang dilarang berdasarkan Keputusan Mentri Negara Lingkungan Hidup nomor 15 tahun 1996 tentang Program Langit Biru, untuk mencegah polusi udara. Azolla merupakan tanaman jenis paku air yang hidupnya 
bersimbiosis dengan Cyanobacteria yang dapat memfiksasi $\mathrm{N}_{2}$. Tanaman ini secara tidak langsung mampu mengikat nitrogen bebas yang ada di udara dan dengan bantuan mikroorganisme Anabaena azollae, nitrogen bebas yang diikat dari udara akan diubah menjadi bentuk yang tersedia bagi tumbuhan. Simbiosis ini menyebabkan Azolla mempunyai kualitas nutrisi yang baik. Azolla sering ditemukan di lahan pertanian terutama pada sawah-sawah yang biasa digenangi.

Pertumbuhan Azolla dilahan sawah pada masa produksi tanaman padi lebih dianggap sebagai tanaman pengganggu (gulma), sehingga penanganan Azolla dilakukan sebagaimana terhadap gulma lainnya. Pengendalian Azolla di lahan sawah biasanya dilakukan dengan cara teknis mekanik, yaitu mengeluarkan Azolla dari dalam lahan secara mekanik baik dengan menggunakan alat ataupun secara manual [5]. Oleh karena itu azolla perlu dimanfaatkan agar saat produksi azolla yang dianggap mengganggu bisa digunakan untuk pembuatan pupuk bukan dimusnahkan.

\section{Teori}

Pengomposan adalah sarana untuk mengubah berbagai limbah organik menjadi produk yang dapat digunakan dengan aman dan menguntungkan sebagai pupuk hayati. Fungsi utama kompos adalah membantu meningkatkan fisik, kimia dan biologi tanah [6]. Metode pengomposan dibagi menjadi dua yakni pengomposan aerobik dan anaerobik. Pengomposan aerobik lebih mudah diterapkan dan apabila diterapkan dengan benar dapat mereduksi volume limbah padat walaupun metode ini juga harus dapat memberikan suplai oksigen ke dalam tumpukan limbah padat. Sedangkan pengomposan anaerobik lebih sulit untuk diterapkan namun produksi metana lebih mudah untuk dikontrol dan dimanfaatkan [8].

Takakura Home Method adalah metode pengomposan yang dikembangkan oleh Mr Koji Takakura, seorang insinyur lingkungan dari JPec Co. Ltd untuk memecahkan masalah pengelolaan sampah di Surabaya. Hal ini dilaksanakan pada tahun 2004 sebagai metode pengomposan yang bertujuan untuk memecahkan masalah pengolahan limbah padat masyarakat, terutama dalam mengelola masalah limbah kota [9].

Takakura adalah sebuah komposter yang terbuat dari keranjang yang dilapisi dengan karpet pada bagian dalamnya, yang bertujuan untuk mencegah masuknya serangga. Metode pengomposan dengan Takakura ini memungkinkan untuk pembuatan kompos yang mudah, higienis dan berkualitas baik dalam waktu yang singkat.

Banyak penelitian sebelumnya telah dilakukan untuk mengetahui proses pengomposan terbaik. Nutongkaew, dkk melakukan pengomposan TKKS dengan campuran Palm Oil Mill Biogas Sludge (POMS) dan Decanter Cake (DC) menggunakan variasi perbandingan, dengan ukuran potongan TKKS 1 $\mathrm{cm}-4 \mathrm{~cm}$ dan pengadukan setiap 10 hari sekali. Hasil penelitian ini diperoleh pengomposan TKKS dengan campuran Palm Oil Mill Biogas Sludge dan Decanter Cake menggunakan variasi perbandingan. Hasil didapatkan setelah 60 hari, kompos terbaik adalah variasi POMS:PEFB:DC yaitu $0,5 \%$ : $0,25 \%: 0,25 \%$, dengan $\mathrm{C} / \mathrm{N} 13,47 \%$ dan $\mathrm{pH}$ basah yaitu 7,79.

Penelitian yang dilakukan oleh Tambunan dilakukan dengan memotong ukuran TKKS sesuai variasi, kemudian dimasukkan kedalam keranjang Takakura dan ditambahkan POA hingga moisture content (MC) bahan mencapai MC optimum yaitu 55\% - 65\% dan variasi ukuran potongan TKKS yang dilakukan adalah $<1 \mathrm{~cm}, 1 \mathrm{~cm}-3 \mathrm{~cm}, 4 \mathrm{~cm}-7 \mathrm{~cm}, 8 \mathrm{~cm}-11 \mathrm{~cm}$, dan $12 \mathrm{~cm}-15 \mathrm{~cm}$. Hasil penelitian yang didapatkan menunjukkan bahwa rata-rata kompos telah masak dalam waktu \pm 40 hari dan degradasi terbaik selama 40 hari diperoleh pada ukuran potongan $1 \mathrm{~cm}-3 \mathrm{~cm}$ dengan dengan $\mathrm{pH}$ 9, MC $52,69 \%$, water holding capacity $76 \%, \mathrm{C}$ $23,81 \%, \mathrm{~N} 1,96 \%$ dan $\mathrm{C} / \mathrm{N} 12,15$.

\section{Metodologi Penelitian \\ Bahan Baku Penelitian}

Bahan baku utama yang digunakan adalah TKKS dari pabrik kelapa sawit Tunas Harapan Sawit Dolok Masihul, Azolla microphylla, pupuk cair organik aktif (PCOA) hasil pengolahan limbah cair pabrik kelapa sawit dari Pilot Plant Pembangkit Listrik Tenaga Biogas, Pusdiklat LPPM, USU.

\section{Prosedur Penelitian}

Komposter keranjang kosong ditimbang beratnya. TKKS dipotong dengan ukuran $1 \mathrm{~cm}$ $3 \mathrm{~cm}$. Campuran TKKS dan Azolla dengan variasi yang telah ditentukan dimasukan ke dalam komposter sebanyak $2 \mathrm{~kg}$ (hingga keranjang penuh). Ditambahkan PCOA hingga mencapai MC pengomposan 55\% - 65\% dan dijaga MC dengan cara penambahan selama proses pengomposan terjadi.

\section{Hasil}

\section{Profil dan Analisis Kompos Berdasarkan Suhu dan MC}

Keberlangsungan proses pengomposan pada campuran $60 \%$ : $40 \%$ berat TKKS dan 
Azolla mycrophilla dapat dilihat dari perubahan suhu dan MC selama proses pengomposan.

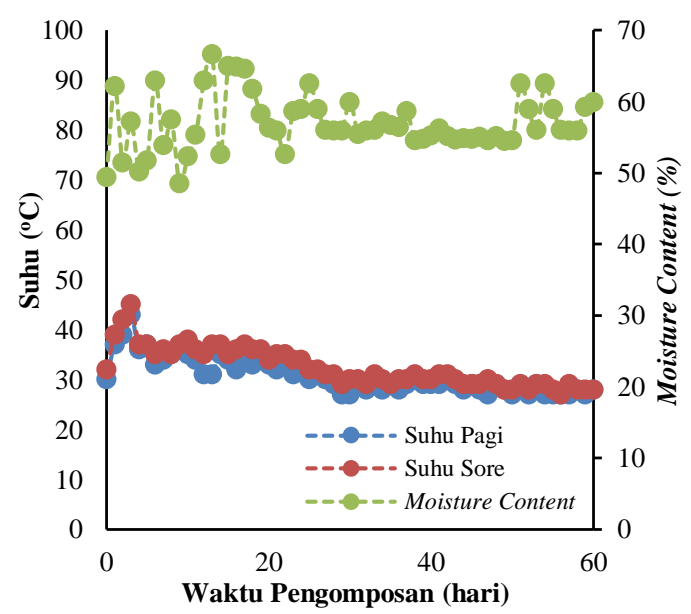

\section{Gambar 1. Profil suhu dan MC selama Pengomposan}

Profil suhu cenderung menurun selama proses pengomposan walaupun ada beberapa titik yang naik tetapi relatif kecil, kenaikan terjadi pada hari ke 6-9, 14-15, 16-17, 18-19, 2122, 23-24, 25-26, 30-31, 32-33, 34-35, 41-42, 5253 dan 59-60. Suhu rata-rata maksimum pada pengomposan ini adalah $45^{\circ} \mathrm{C}$. Setelah itu, suhu perlahan mulai menurun sampai hari ke-60 . Hal ini sesuai dengan yang dilaporkan oleh Shen et al. dan Siong et al, mereka menyatakan bahwa setelah peningkatan suhu yang cepat selanjutnya perlahan-lahan suhu akan menurun dan ini mengindikasikan bahwa proses degradasi melambat seiring dengan menipisnya ketersediaan nutrisi [10].

MC adalah parameter penting untuk mengoptimalkan proses pengomposan. Menurut Siong et al., ketergantungan mikroba terhadap air untuk mendukung pertumbuhannya dapat mempengaruhi biodegradasi bahan-bahan organik [10]. Pada penelitian ini, penambahan PCOA ke TKKS dan Azolla mycrophilla selain untuk menambah mikroba dan nutrisi, juga untuk mempertahankan nilai MC berkisar 55\%-65\%. MC awal sebelum penambahan PCOA adalah 49,39\% lalu ditambahkan PCOA sebanyak $0,4877 \mathrm{~kg}$ sehingga nilai MC menjadi $62,17 \%$. Hal tersebut sesuai dengan yang dilaporkan Tiquia et al. bahwa tingginya suhu dalam pengomposan bisa menyebabkan hilangnya air terus-menerus dalam bentuk penguapan [14]. MC akhir diperoleh sebesar 59,92\%. Nilai ini mendekati dengan nilai MC yang dipoeroleh pada penelitian-penelitian sebelumnya. Seperti yang dilaporkan Siong et al. (2009), diperoleh MC 50\% [5], dan Bahruddin et al (2010), memperoleh MC sebesar $52 \%$ [10]. Tiquia et al. (2001), juga melaporkan bahwa kadar air sekitar $40 \%$ sampai $60 \%$ diperlukan untuk kelangsungan hidup mikroorganisme sementara itu kadar melebihi $80 \%$ bisa membunuh mikroba aerobik karena kekurangan udara [4]. Oleh karena itu, penambahan PCOA sangat penting untuk mempertahankan aktifitas biologis serta menyediakan sumber nitrogen.

\section{Analisis Kompos Berdasarkan pH}

Untuk melihat keberlangsungan proses pengomposan, maka perlu diukur $\mathrm{pH}$ kompos dalam komposter setiap hari sekali.

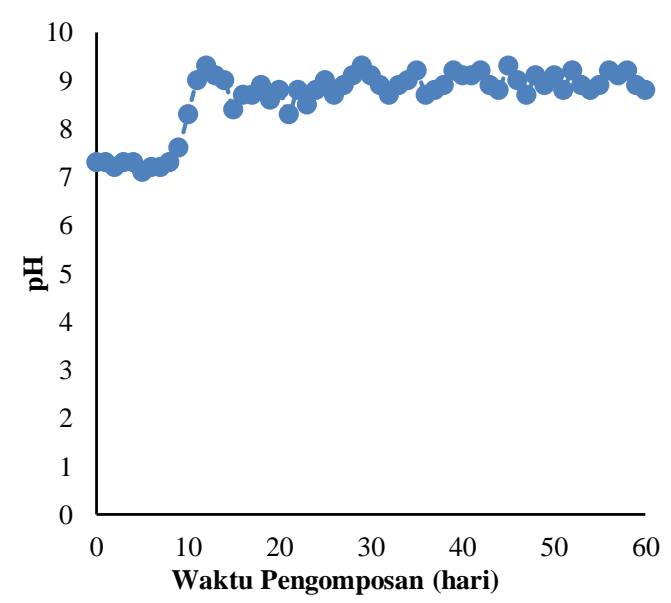

Gambar 2. Profil pH selama pengomposan

Rentang pH selama 60 hari pengomposan adalah berkisar antara 7,1 hingga 9,3 yang menunjukkan kondisi cenderung basa. Selama pengomposan $\mathrm{pH}$ fluktuatif namun cenderung naik. Dapat dilihat pada gambar bahwa pada hari ke $10 \mathrm{pH}$ mengalami peningkatan yang signifikan. Perubahan $\mathrm{pH}$ selama proses pengomposan disebabkan oleh aktivitas mikroba [3]. Kenaikan $\mathrm{pH}$ terjadi karena $\mathrm{N}$ berubah menjadi $\mathrm{NH}_{3}$ atau $\mathrm{NH}_{4}{ }^{+}$dalam proses amonifikasi, sehingga $\mathrm{pH}$ meningkat. Penurunan $\mathrm{pH}$ disebabkan oleh proses penguapan ammonium dan pelepasan ion hidrogen sebagai akibat dari proses nitrifikasi [12]. Secara keseluruhan kondisi yang terjadi selama pengomposan cenderung basa yaitu dengan rentang 7,1- 9,3. Hal ini terjadi karena adanya pengadukan yang dilakukan dalam rentang 3 hari sekali. Dengan dilakukannya pengadukan dapat mengeluarkan $\mathrm{CO}_{2}$ yang terperangkap dalam ruang kosong antar partikel kompos, sehingga mencegah terjadinya kondisi asam pada tumpukan atau penurunan $\mathrm{pH}$ yang signifikan [8]. Meningkatnya $\mathrm{pH}$ menjadi kondisi basa baik untuk proses pengomposan. Karena kondisi basa 
dapat menghambat pertumbuhan patogen seperti jamur yang dapat hidup dalam kondisi asam [11].

\section{Analisis Kompos Berdasarkan Perbandingan $\mathbf{C} / \mathbf{N}$}

Untuk mengetahui kualitas kompos yang dihasilkan, maka perlu diukur perbandingan $\mathrm{C} / \mathrm{N}$ yang dilakukan 10 hari sekali selama proses pengomposan.

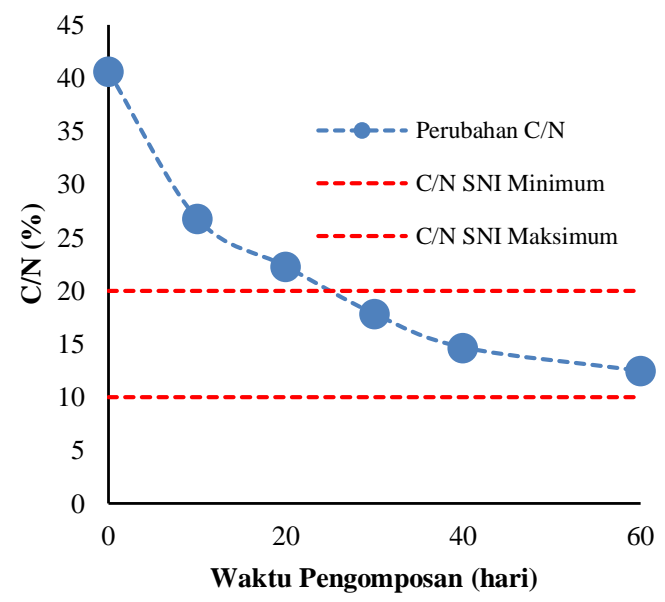

Gambar 3. Profil Nilai C/N selama Pengomposan

Pada pengomposan ini, menggunakan campuran 60\%: $40 \%$ berat TKKS dan Azolla mycrophilla yang dipotong dengan ukuran $1 \mathrm{~cm}$ - $3 \mathrm{~cm}$ dan pengadukan 3 hari sekali. $\mathrm{C} / \mathrm{N}$ dianalisa sebanyak 6 kali selama proses pengomposan dari hari ke-0 sampai hari ke-40 dan hari ke-60. Nilai $\mathrm{C} / \mathrm{N}$ sebelum perlakuan adalah $40,61 \%$, setelah proses pengomposan nilai $\mathrm{C} / \mathrm{N}$ berkurang drastis menjadi $26,78 \%$ pada hari ke-10. Pada hari ke-20 nilai $\mathrm{C} / \mathrm{N}$ menurun menjadi 22,27\%. Pada hari ke-30 nilai $\mathrm{C} / \mathrm{N}$ menurun menjadi $17,80 \%$. Pada hari ke-40 nilai $\mathrm{C} / \mathrm{N}$ menurun menjadi $14,66 \%$. Pada hari ke-60 nilai $\mathrm{C} / \mathrm{N}$ menurun menjadi $12,45 \%$. Penurunan nilai perbandingan $\mathrm{C} / \mathrm{N}$ adalah akibat penurunan kadar C selama pengomposan. Hal ini terjadi karena adanya proses dekomposisi bahan organik dari hasil aktivitas mikroba [9]. Nilai perbandingan $\mathrm{C} / \mathrm{N}$ merupakan salah satu indikator penting yang menyatakan kematangan kompos [7]. Campuran kompos awal memiliki nilai perbandingan $\mathrm{C} / \mathrm{N} 40,61 \%$ dan hasil akhir pengomposan menunjukkan nilai perbandingan $\mathrm{C} / \mathrm{N}$ menjadi $12,45 \%$.

\section{Analisis Kompos Berdasarkan Electrical Conductivity (EC)}

Untuk mengetahui jumlah garam terlarut dalam menentukan kualitas kompos, perlu dilakukan analisa EC. EC mencerminkan tingkat salinitas dalam suatu produk kompos, yang menunjukkan kemungkinan efek phytotoxic atau phyto-inhibitory [15].

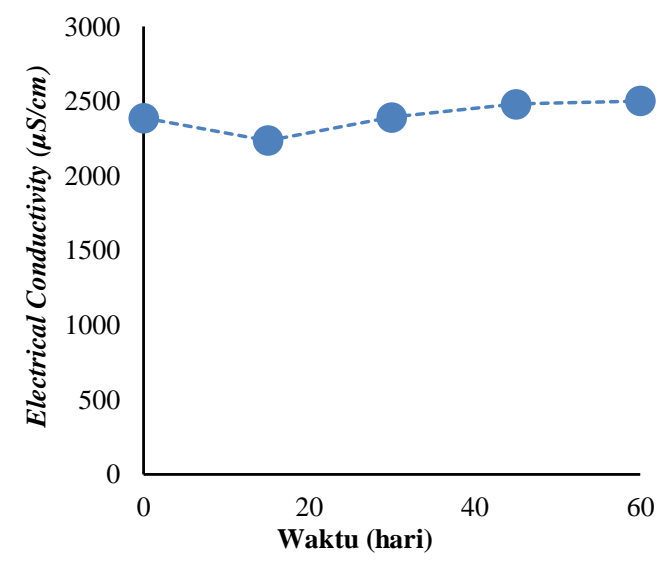

Gambar 5. Profil Nilai EC selama Pengomposan

Pada Gambar terlihat perubahan nilai EC selama waktu pengomposan. Nilai EC kompos

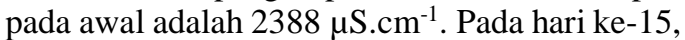
nilai EC kompos mengalami penurunan yaitu $2236 \mu$ S. $\mathrm{cm}^{-1}$. Kemudian pada hari ke-30, nilai EC mengalami peningkatan yaitu $2392 \mu \mathrm{S} \mathrm{cm}^{-1}$. Nilai EC kembali meningkat pada hari ke-45 yaitu $22482 \mu \mathrm{S} . c m^{-1}$ dan nilai EC akhir yang didapat setelah proses pengomposan ini adalah $2502 \mu \mathrm{S} . \mathrm{cm}^{-1}$. Penurunan nilai EC selama proses pengomposan adalah akibat langsung dari peningkatan konsentrasi nutrisi seperti nitrat dan nitrit[10]sedangkan peningkatan nilai EC dapat disebabkan karena pelepasan garam-garam mineral seperti ion-ion Fosfat dan Ammonia melalui dekomposisi dari substansi organik [13].

\section{Kesimpulan}

Kompos campuran 60:40 \% berat tandan kosong kelapa sawit dan Azolla microphylla dengan bantuan PCOA sebagai sumber mikroba, sumber nutrisi dan penyangga MC terbukti dapat menghasilkan kompos lebih kurang 30 hari. dengan karakteristik $\mathrm{pH} 8,8, \mathrm{MC} 59,92 \%$, water holding capacity $86 \%$, C 27,24\%, N 1,53\%, dan perbandingan $\mathrm{C} / \mathrm{N} 17,80 \%$.

\section{Daftar Pustaka}

[1] A. Haryanti, Norsamsi, P. S. F. Sholiha, N. P. Putri, Studi Pemanfaatan Limbah Padat Kelapa Sawit, Jurnal Konversi, 3 (2) (2014) 20-29.

[2] A. S. Baharuddinn, L. S. Hock, M. Z.Yusof, N. A. A. Rahman, U. K. Shah, M. A. Hassan, M. Wakisaka, K. Sakai, Y. Shirai, Effects of Falm Oil Mill Effluent (POME) Anaerobic Sludge From $500 \mathrm{~cm}^{3}$ of Closed Anaerobic Methane Digested Tank on Pressed-Shredded Empty Fruit Bunch (EFB) 
Composting Process, African Journal of Biotechnology, 9 (16) (2010) 2427-2436.

[3] A. Y. Zahrim, dan T. Asis, Production Of Non Shredded Empty Fruot Bunch Semi Compos, Journal The Institution of Engineers Malaysia, 71(4) (2010) 11-17.

[4] Anonim, Seperation at Source, Collection and Composting of Waste in Surabaya Promoting the Reduction and Recycling of Waste, Kitakyushu International TechnoCooperative Association, Indonesia, 2007, p. 11.

[5] B. Sudjana, Penggunaan Azolla untuk Pertanian Berkelanjutan, Jurnal Ilmiah, 1 (2) (2014) 72-81.

[6] B. Trisakti, M. P. Hardela, T. Husaini, Irvan, H. Daimon, Production of oil palm empty fruit bunch compost for ornamental plant cultivation, IOP Conference Series Materials Science and Engineering, Medan, Indonesia, 2018, p. 2.

[7] British Colimbia Ministry of Agriculture and Food, The Composting Process. Ministry of Agriculture and Food of British Colimbia, 1996.

[8] G. Tchobanoglous, Integrated Solid Waste Management, Mc Graw-Hill, 1993, p.213.

[9] G. Y. Huei, dan M. H. Ibrahim, Local Knowledge In Waste Management: A study Of Takakura Home Method, Journal of Science and Technology, 2 (3) (2013) 528533.

[10] L. S. Hock, A. S. Baharuddin, M. N. Ahmad, U. K. M. Shah, N. A. A. Rahman, S. A. Aziz, M. A. Hassan, Y. Shirai, Physicochemical Changes in Undrow CoComposting Process of Oil Palm Mesocarp Fiber and Palm Oil Mill Efluent Anaerobic Sludge, Australian Journal of Basic and Applied Sciences. 3 (3) (2009) 2809-2816.

[11] N. Saidi, M. Cherif, M. Mahrouk, M. Fumio, A. Boudabous, A. Hassen, Evaluation of biochemical parameters during composting of various wastes compost, American, Journal of Environmental Sciences 4 (4) (2008) 332341.

[12] N. Sekarsari, Pengaruh Frekuensi Pengadukan Terhadap Proses Pengomposan Open Windrow (Studi Kasus : UPS Jalan Jawa, Kota Depok), Skirpsi, Universitas Indonesia, Depok, 2011.

[13] R. Rynk, On-Farm Composting Handbook. Northeast Regional Agricultural Engineering Service, New York, 1992, p. 89.
[14] S. M. Tiquia, J. H. C. Wan, N. F. Y. Tam, Dynamics of Yard Trimmings Composting as Determined by Dehydrogenase Activity, ATP Content, Arginie Ammonification, and Nitrification Potential, Journal Process Biochemistry, 37 (2002) 1057-1065.

[15] T. Carballo, M.V. Gil, L.F. Calvo, A. Moran, The Influence of Aeration System, Temperature and Compost Origin on the Phytotoxicity of Compost Tea, Journal of Compost Science \& Utilization, 17 (2) (2009) 127-139. 